\title{
ОСОБЕННОСТИ СОДЕРЖАНИЯ КРУПНОГО РОГАТОГО СКОТА НА ТЕРРИТОРИИ ЛЕНИНГРАДСКОЙ ОБЛАСТИ
}

\author{
Губернаторова Виктория Александровна \\ студент 2 курса \\ Научный руководитель: Кузнецова Татьяна Шамильевна \\ доцент, кандидат биологических наук \\ ФГБОУ ВО “Санкт-Петербургский государственный \\ университет ветеринарной медицины”
}

\begin{abstract}
Аннотация: работа представляет собой исследование современных способов содержания крупного рогатого скота на территории хозяйств Ленинградской области с численностью в 2000-3000 голов и показателей их продуктивности, а также выявление характерных заболеваний поголовья каждого из хозяйств.
\end{abstract}

Ключевые слова: КРС, привязное содержание, беспривязное содержание, престартеры, язва Рустергольца, тилома, смещение сычуга.

\section{FEATURES OF KEEPING CATTLE ON THE TERRITORY OF THE LENINGRAD REGION}

\section{Gubernatorova Victoriia Aleksandrovna Scientific adviser: Kuznetsova Tatiana Shamilevna}

\begin{abstract}
: the work is a study of modern methods of keeping cattle on the territory of farms of the Leningrad region with a population of 2000-3000 heads and indicators of their productivity, as well as the identification of characteristic diseases of the livestock of each of the farms.

Key words: cattle, tethered keeping of an animal, loose keeping of an animal, prestarters, Rustergoltz ulcer, tiloma, abomasum displacement.

Скотоводство - это одна из ведущих отраслей сельского хозяйства. В настоящее время она занимает лидирующее положение среди других отраслей животноводства. Однако, для поддержания лидирующих позиций
\end{abstract}


скотоводческие хозяйства должны придерживаться определенных норм содержания, а также совершенствовать технологии, которые применяются в производстве. При несоблюдении данных аспектов, возможно появление заболеваний среди крупного рогатого скота, в следствие чего будут снижены показатели продуктивности (удои, МДЖ, МДБ, убойная масса), из-за которых многие сельскохозяйственные предприятия понесут большие экономические убытки.

Существуют два основных способа содержания крупного рогатого скота, виды которого зависят от физиологического состояния животных, их возраста, пола, а также особенностей самого предприятия (его экономических ресурсов, современности оборудования, количества рабочей силы) и климатических условий, обусловленных уникальностью географического расположения. К ним относится: привязное и беспривязное содержание крупного рогатого скота. Основным существенным различием между ними является наличие или отсутствие свободного передвижения животного. При беспривязном способе- животные содержатся в группах без привязи, имеют возможность передвигаться по секции, отведенной для них, свободно получают доступ к кормам. При привязном способе животные находятся в условиях ограниченной подвижности, могут содержаться на привязи в групповых стойлах или же в индивидуальных боксах $[1$, с. 22]. Каждый из способов имеет свои положительные и отрицательные черты. Помимо этого, имеется возможность комбинированного содержания крупного рогатого скота в разных возрастных группах на территории одного хозяйства.

Цель работы: выявить особенности разных типов содержания и их влияние на продуктивность, а также возможность возникновения заболеваний у крупного рогатого скота.

Объектом изучения было поголовье крупного рогатого скота двух скотоводческих хозяйств молочного направления продуктивности на территории Ленинградкой области

Методы, используемые в работе: анализ информации по содержанию животных двух скотоводческих хозяйств Ленинградской области, степень распространения заболеваний, сравнение с ветеринарными стандартами.

Положительные и отрицательные стороны разных способов содержания КРС представлены в таблице 1. 


\section{Таблица 1}

Особенности привязного и беспривязного содержания крупного рогатого скота

\begin{tabular}{|c|c|c|}
\hline & \multicolumn{2}{|c|}{ Способы содержания КРС } \\
\hline & Привязное & Беспривязное \\
\hline $\begin{array}{l}\text { Положительные } \\
\text { особенности }\end{array}$ & $\begin{array}{l}\bullet \text { Возможность } \\
\text { индивидуального подхода } \\
\text { к работе с каждым } \\
\text { животным. } \\
\text { • Доступность в } \\
\text { проведении ветеринарных } \\
\text { манипуляций. } \\
\text { • Обеспечивается } \\
\text { тщательный контроль за } \\
\text { каждым животным в } \\
\text { стаде. }\end{array}$ & $\begin{array}{l}\text { • Обеспечивает проведение } \\
\text { манипуляций и контроля с } \\
\text { большим количеством поголовья } \\
\text { • } \quad \text { Автоматизирование } \\
\text { технологических процессов } \\
\text { • Требует меньшего количества } \\
\text { обслуживающего персонала (чем } \\
\text { обуславливается снижение } \\
\text { экономических затрат на } \\
\text { сотрудников) } \\
\text { • Способствует сохранению } \\
\text { среднестатистических } \\
\text { показателей продуктивности } \\
\text { среди стада } \\
\text { • Обеспечение двигательной } \\
\text { активности животного, } \\
\text { предупреждение развития } \\
\text { заболеваний опорно- } \\
\text { двигательного аппарата }\end{array}$ \\
\hline $\begin{array}{l}\text { Отрицательные } \\
\text { особенности }\end{array}$ & $\begin{array}{l}\text { • Необходимость } \\
\text { большого количества } \\
\text { рабочей силы } \\
\text { (обслуживающий } \\
\text { персонал) } \\
\text { • Возможно снижение } \\
\text { удоев вследствие } \\
\text { ограниченной } \\
\text { подвижности животного }\end{array}$ & $\begin{array}{l}\text { • } \quad \text { При неисправности } \\
\text { оборудования возможны } \\
\text { задержки производства на } \\
\text { длительное время } \\
\text { • } \quad \text { Необходимость наличия } \\
\text { современного и качественного } \\
\text { оборудования (дороговизна } \\
\text { технологий) } \\
\text { • Требуется } \\
\text { высокоспециализированный } \\
\text { персонал, который может } \\
\text { обращаться с техническим } \\
\text { оборудованием } \\
\text { • } \quad \text { Высока вероятность } \\
\text { травматизации животного в стаде } \\
\text { при передвижении по территории }\end{array}$ \\
\hline
\end{tabular}


Таким образом, можно сказать, что беспривязное содержание является наиболее приемлемым вариантом для хозяйств с большой численностью поголовья, в котором работа обеспечивается за счет механизации всего процесса, в то время, как привязное содержание обуславливает индивидуальный подход к каждому животному в стадах $\mathrm{c}$ меньшей численностью [2, с. 870].

Для выявления особенностей организации комплексов и рабочего процесса предприятий, специализирующихся на беспривязном и комбинированном способе содержания крупного рогатого скота, были изучены характеристики 1-ого и 2-ого хозяйств, находящихся на территории Ленинградской области (табл. 2).

Таблица 2

Характеристики исследуемых хозяйств

\begin{tabular}{|l|c|c|}
\hline Порода & 1-ое хозяйство & 2-ое хозяйство \\
\hline $\begin{array}{l}\text { Численность } \\
\text { поголовья, гол. }\end{array}$ & $\begin{array}{c}\text { Голштинизированная } \\
\text { черно-пестрая }\end{array}$ & $\begin{array}{c}\text { Голштинизированная } \\
\text { черно-пестрая }\end{array}$ \\
\hline $\begin{array}{l}\text { Дойное } \\
\text { поголовье, гол. }\end{array}$ & 3000 & 2000 \\
\hline
\end{tabular}

На территории 1-ого хозяйства расположено 4 больших двора, в которых животные распределены, в зависимости от физиологического состояния и возраста: 1 двор - для новорожденных телят и молодняка, 2 двор - для дойного стада, 3 двор - для нетелей и осемененных коров, 4 двор - для дойных коров. В каждом дворе есть определенные секции, в которых животные разделены на небольшие группы. Помимо этого, на территории хозяйства располагаются выгульные площадки, на которых животные группами около 100 голов находятся под открытым небом на протяжении нескольких часов в сутки (рис. 1).

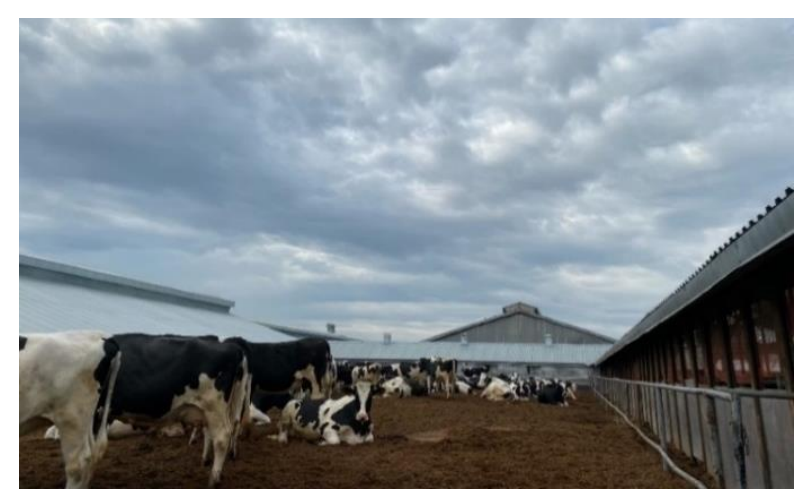

Рис. 1. Выгульный двор

84 
Территория 2-ого хозяйства занимает большую площадь и поделена на 9 дворов, в каждом из которых находятся животные определенных возрастов (1 профилакторий для телят и молодняка, со 2 по 4 включительно - дворы для нетелей и первотелок, 6-8 - для дойного стада, 9 - для больных животных). В каждом из дворов содержание животных отличается.

Содержание телят в 1-ом хозяйстве - групповое, основанное на помещении телят в индивидуальные клетки на первый месяц (рис. 2), а затем формировании из них небольших групп (10-15 голов). При этом клетки для бычков и для телок находятся в разных областях двора для молодняка. Каждая клетка оборудована индивидуальной кормушкой и поилкой, а внутриподстилка из соломы. Каждый день работники телятника проводят уборку навоза, а также следят за общим состоянием поголовья. При этом очень важное значение при уходе за телятами имеет кормление.

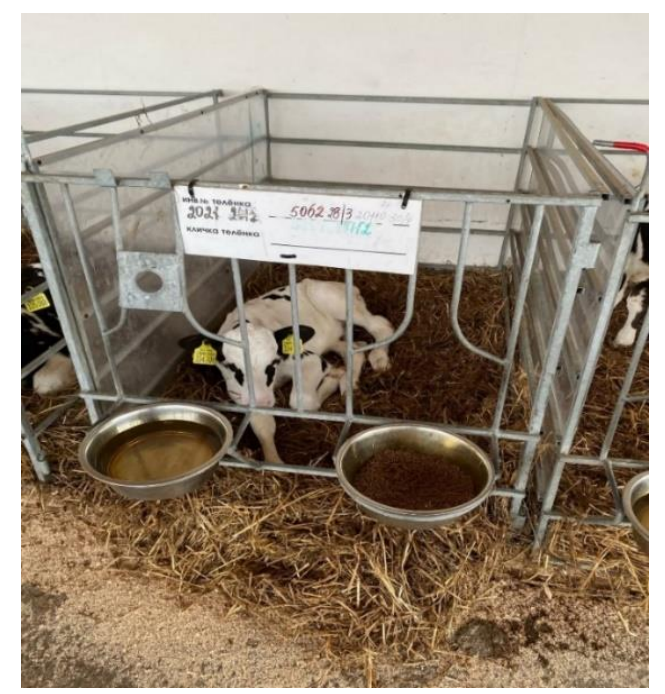

\section{Рис. 2. Индивидуальная клетка для теленка}

В первые 5 дней после рождения телят выпаивают цельным молоком, полученным от матери, для обеспечения формирования иммунитета у теленка, а затем, по окончании 3-ей недели переводят на более грубые корма, при этом переход осуществляют плавно, с постепенным добавлением порций. В качестве престартерного корма применяют МУММ 7703, который представляет собой концентрат. При его попадании в рубец, он подвергается ферментации, и выделяемая масляная и пропионовая кислоты, которые обеспечивают рост ворсинок рубца. Корм содержит сырой протеин - 22\%, обменная энергия - 12,2 МДж/кг. Он подается в свободном доступе, но при обязательном наличии воды в поилках. Кормят им примерно до 4 месяцев. 
Данный корм способствует поступлению белка, витаминов, минералов в организм животного, что обеспечивает нормальный рост и формирование костно-мышечной ткани. Выход телят на 100 коров составляет 84 головы.

На территории 2-ого хозяйства родившиеся телята в первые 5 дней содержатся в первой секции профилактория на привязи (рис. 3). При этом рабочий персонал каждый день выпаивает телят цельным молоком, следит за чистотой и состоянием поголовья. Далее до 3 месячного возраста их переводят во вторую секцию телятника, где животных уже объединяют в небольшие группы, приучая к престартерным кормам (комбикорма) и воде (делают это постепенно). Выход телят на 100 коров составляет 83 головы.

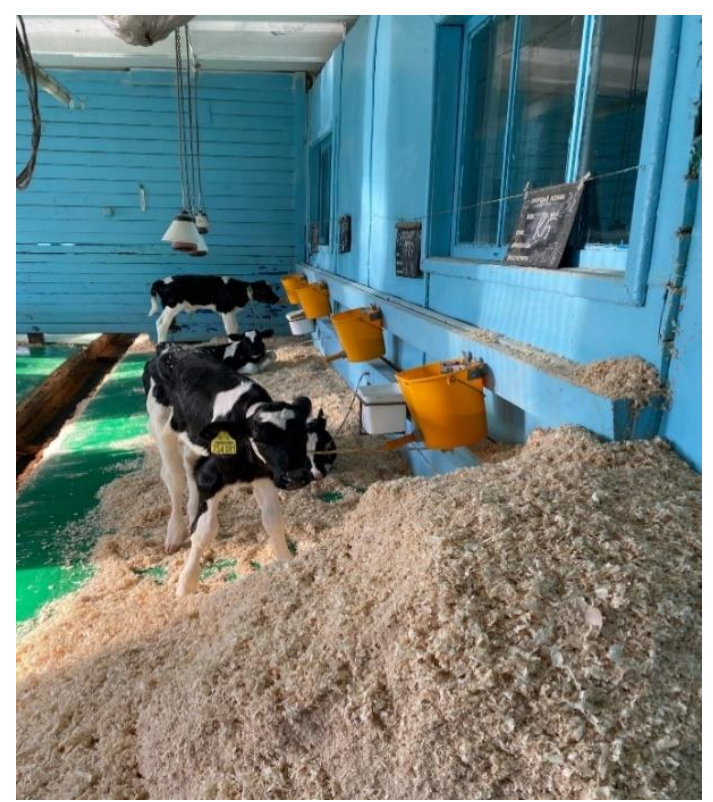

Рис. 3. Привязное содержание телят

Далее подросший молодняк формируют по группам, при этом бычков отправляют на продажу, а телочек переводят в следующий сектор, где уже на территории 1-ого и 2-ого хозяйства содержатся, так же, как и нетели и первотелки, а также дойное стадо, беспривязно. Стоит отметить, что на территории двух хозяйств используют разновидность беспривязного содержания - боксовое содержание, при котором, вместо глубокой подстилки имеются специальные “зоны отдыха" для коров, огражденные тремя перегородками (рис. 4). Помимо этого, на территории 1-ого хозяйства имеются специальные автоматизированные щетки для коров, которые являются универсальным средством гигиены, обеспечивающим чистку животных от грязи и насекомых [3, с. 10948]. 


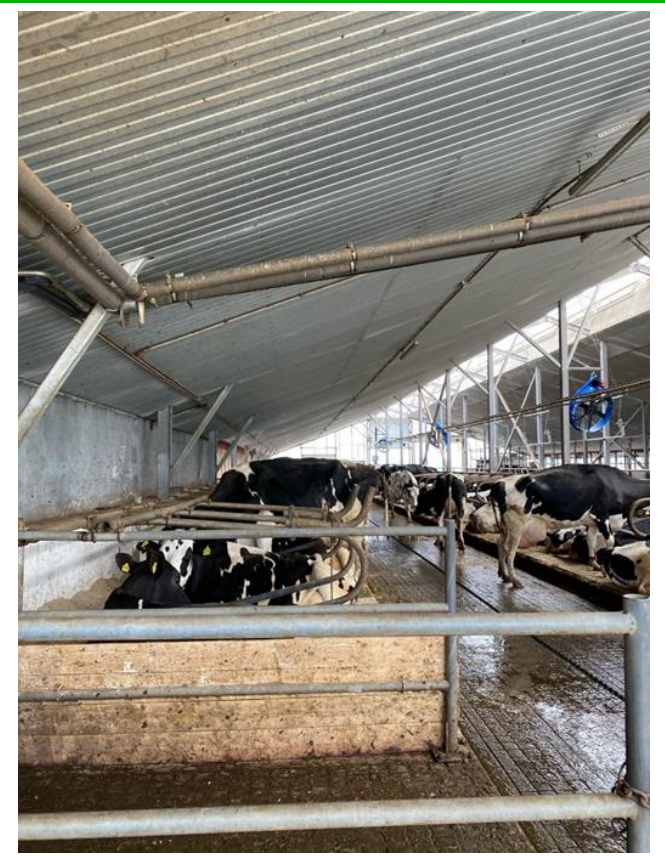

\section{Рис. 4. Беспривязное содержание крупного рогатого скота}

Кормление животных 1-ого хозяйства преимущественно силосносенное, а 2-ого-силосно-сенажное (рис. 5). Корма размещают на общих “кормовых столах” перед секциями 3 раза в день - у 1-ого хозяйства, 2 раза в день - у 2-ого хозяйства. Поение осуществляется за счет работы автоматизированных поилок.

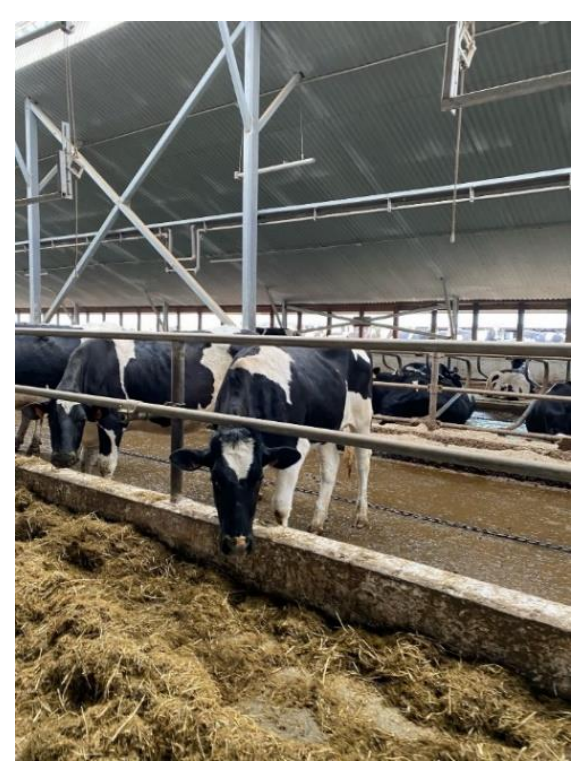

Рис. 5. Кормление коров при беспривязном содержании

По достижении 18-месячного возраста, а также при наборе живой массы $65-75 \%$ от массы взрослого животного, телок искусственно осеменяют в специальной секции (или дворе на территории 2-ого хозяйства). Осеменение 
проводят наиболее эффективным из известных способов ректо-цервикальным (глубоким), когда шприц/пипетку с семенем вводят во влагалище животного, контролируя при этом движение через прямую кишку. Последовательность работы: 1) с помощью левой руки (в перчатке) из прямой кишки коровы удаляются каловые массы; 2) наружные половые органы обрабатывают раствором фурацилина; 3) рука в перчатке обмывается мыльным раствором и снова помещается в задний проход; 4) производится пальпация матки и яичников на предмет отсутствия желтого тела; 5) свободной рукой раздвигается половая щель самки; 6) инструмент вводится до упора по верхнему своду влагалища; 7) рукой в прямой кишке захватывается шейка матки;8) мизинцем той же руки определяется конец катетера; 8) шейка «надевается» на инструмент; 9) катетер продвигают вглубь на 6-8 см; 10) производится впрыскивание семени; 11) инструмент извлекается.

В дальнейшем осемененных коров помещают в двор вместе с нетелями. По прошествии примерно 285 суток происходит отел, который проводят в специальной родильной секции. Когда первотелка отелилась, ее начинают доить. Доение осуществляется в специализированных доильных секциях автоматизированным способом, то есть с применением специальной техники. Доение осуществляют 2 раза в сутки (утром и вечером), что благополучно сказывается на сохранении показателей продуктивности без вреда для самой коровы. Среднесуточные надои 1-ого хозяйства составляют примерно $32 \mathrm{~T}$ молока (МДЖ=3,8), 2-ого хозяйства 30 т молока (МДЖ=3,9).

Немаловажное значение в уходе за крупным рогатым скотом, помимо кормления и уборки, играет и расчистка копыт. На территории 1-ого хозяйства ее осуществляют минимум 3 раза в год для каждой коровы. Для ее проведения используют специальное оборудование, которое позволяет безболезненно зафиксировать животное и провести работу максимально эффективно (рис. 6).

Во время работы проводят осмотр и профилактические работы для предотвращения развития инфекционных заболеваний. Для этого на 1-ом хозяйстве используют ванночки с 3-5\% раствором формалина. На территории 2-ого хозяйства нет регулярной расчистки копыт, в следствие недостаточного количества рабочей силы. Периодически нанимают выездных работников для проведения данной процедуры. Но для обеспечения гигиены копыт применяют новую технологию - очистка специальной пеной, содержащей антисептические вещества. Данная процедура проводится по строго 
нормированному графику (через каждые 2 недели утром и вечером после доения). Особенность действия данного средства обусловлена входящими в его состав поверхностно-активными веществами и противомикробными компонентами: оно очищает копыта от грязи; повышает смачивающую способность воды, снижает ее поверхностное натяжение, образуя на поверхности копытного рога биопленку, которая обладает длительным бактериостатическим действием, препятствуя проникновение условнопатогенной микрофлоры.

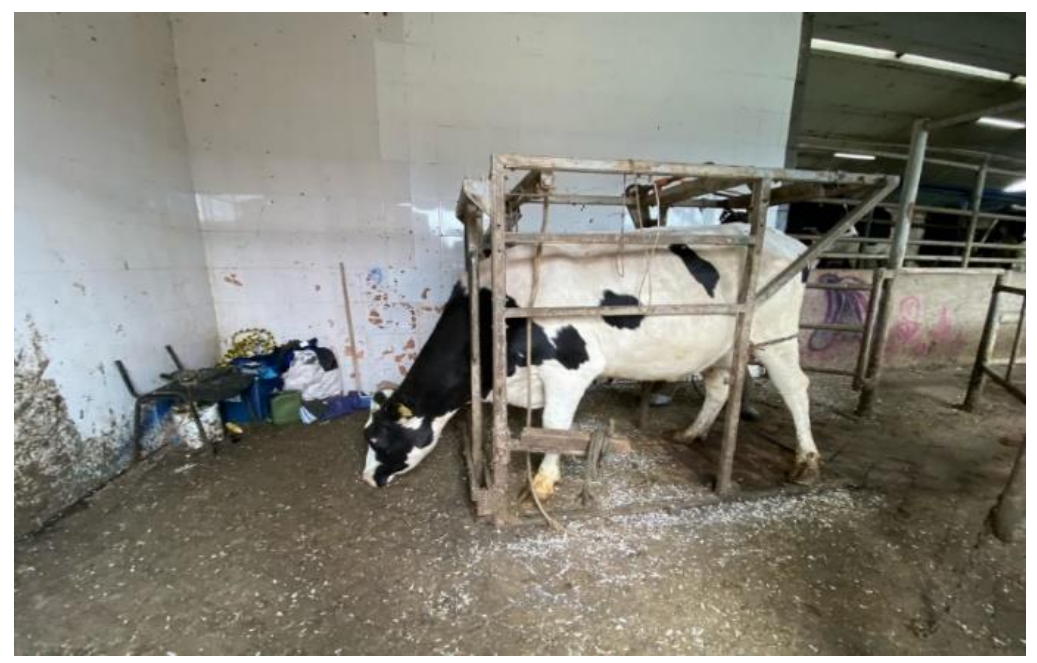

Рис. 6. Расчистка копыт у крупного рогатого скота

В исследуемых хозяйствах есть заболевания, которые имеют широкий спектр распространения, к ним относятся: пододерматиты, язва Рустергольца, болезнь Монтелларо, а также тиломы, маститы, гепатозы, эндометриты. При этом больные животные на территориях двух хозяйств содержатся в отдельных секторах на привязи и подстилке. Стоит отметить, что беспривязное содержание способствует высокому уровню травматизации, вследствие свободного перемещения животных по территории.

Язва Рустергольца - это заболевание копытец КРС, характеризующееся локальным поражением основы кожи копытца. В 1-ом хозяйстве данное заболевание у нетелей и коров встречается значительно реже, из-за регулярной расчистки копыт, что является действенным профилактическим фактором. Наибольшая частота встречаемости характерна для нетелей старших возрастов и коров. Чаще всего поражаются задние конечности, а именно наружные копытца. На передней конечности чаще поражаются внутренние копытца. Болезнь не является заразной, развивается вследствие неправильной нагрузки на копыто (отсутствие моциона, травмы, ожирение). 
При появлении одного или нескольких предрасполагающих факторов происходит чрезмерная нагрузка на одну точку в подошве копыта - это приводит к ухудшению кровообращения в данном участке, что ведет к некрозу тканей $[4$, c. 128]. При образовании некроза рог в пораженном участке не растет и происходит его быстрое истирание, что приводит к появлению язвы на поверхности подошвы. При попадании в рану гноеродных бактерий, особенно анаэробов, может развиться пододерматит всей подошвы. Основной метод лечения, применяемый на территории 2-ух хозяйств-это обрезание копыта, при этом рог убирают так, чтобы он не оказывал давления на язву и обеспечивал поступление кислорода (для предотвращения развития анаэробных инфекций). После этого копыто обрабатывают дёгтем и фурацилином (рис. 7).

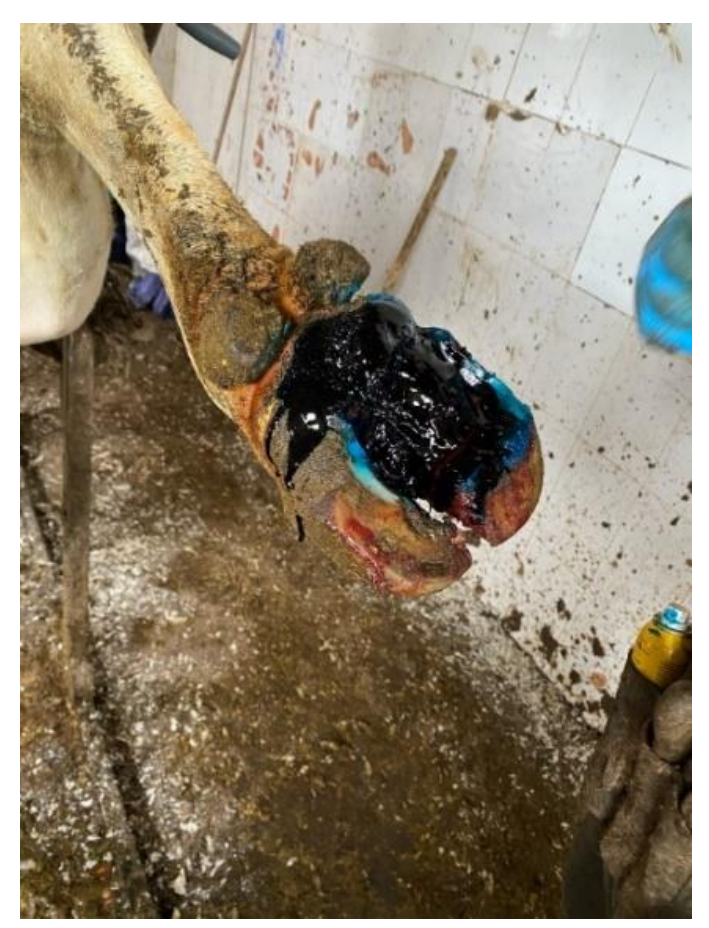

Рис. 7. Обработка дёгтем конечности коровы с язвой Рустергольца

Тилома-хроническое заболевание крупного рогатого скота, характеризующееся разрастанием кожи в межпальцевой щели (фиброма). Наибольшая частота встречаемости характерна для взрослых коров. При раздражении кожи в межпальцевой щели механическими (подстилка) или химическими (навозная жижа, моча) факторами включаются компенсаторные процессы. В коже меж копытной щели происходит гиперплазия эпителия, что приводит к гиперкератозу. Отмечается в основном на тазовых конечностях. В межпальцевой щели виден мясистый нарост размером до 4-5 см (рис. 8). При 
его повреждении животное испытывает боль. Часто на тиломе можно обнаружить дерматит или болезнь Мортелларо. Обычно, при сильном повреждении развивается межпальцевая флегмона. Основной путь лечения заключается в хирургическом удалении тиломы, однако, из-за возможности попадания и разрастания патогенной микрофлоры, работники исключают провоцирующие факторы, а также следят за дальнейшим ростом или же его отсутствием у животного, применяют регулярно ванночки для обеззараживания или пену.

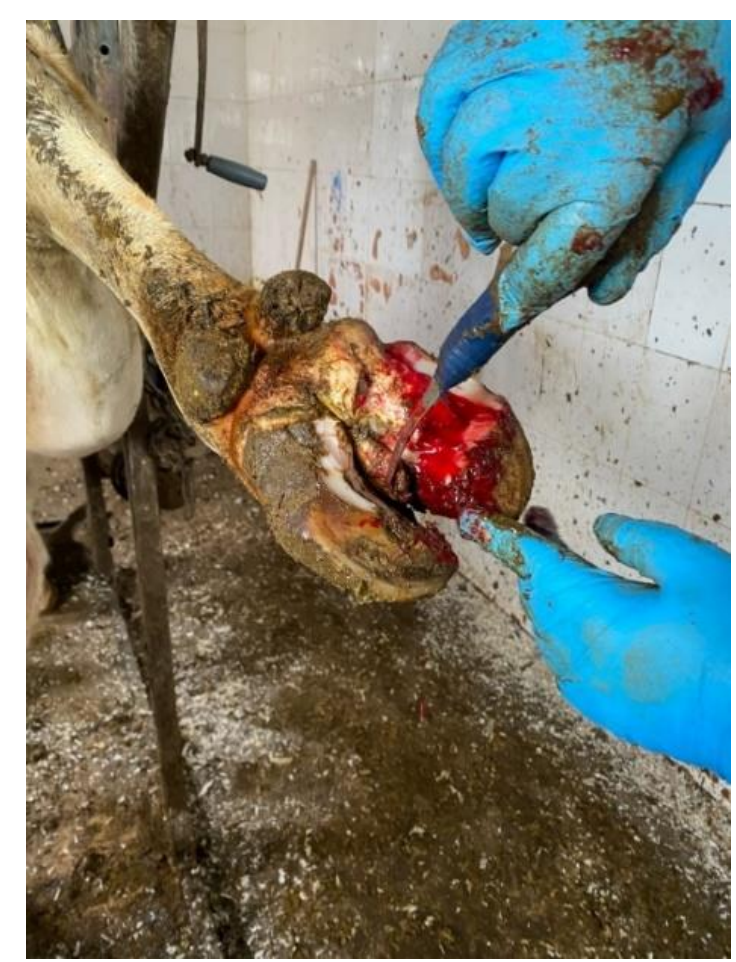

Рис. 8. Тилома у коровы

В ходе выполнения работы были выявлены некоторые отличительные заболевания на территории каждого из хозяйств. Так, в 1-ом хозяйстве наблюдаются случаи смещения сычуга (примерно 76 случаев за последний год). Чаще всего встречается левостороннее смещение, преимущественно в холодное время года (ноябрь-декабрь) у коров после отела. Патологическое состояние вызывается смещением сычуга в левую сторону, где он проходит между наружной поверхностью рубца и левой стенкой брюшины. Образующиеся внутри него газы увеличивают объем камеры сычуга. В запущенных ситуациях он сильно растягивается в брюшной полости животного. Кверху он может достичь поперечных отростков поясничных позвонков, сзади - середины левой брюшной полости [5, с. 65]. При этом, 
местоположение книжки и сетки остается прежним, но обмен веществ может нарушиться и привести к развитию кетозов, истощению животного. Диагностируется заболевание комплексно, на основании клинических признаков (вялость, отказ от корма, снижение массы тела, снижение продуктивности (резкое падение среднесуточных удоев), а также проведении аускультации (слышен металлический звук) и перкуссии. Основной метод лечения заключается в хирургическом вмешательстве - левосторонней, правосторонней и медиальной лапаротомии.

На территории 2-ого хозяйства отмечается наличие бурситов тарсального сустава (рис. 9) и периоститы, преимущественно у первотелок и молодых коров. Бурсит у коров чаще возникает после травмы конечностей или из-за проникновения инфекции. Воспаление синовиальных сумок затрудняет передвижение животного. О заболевании свидетельствует появление хромоты. Травмированная конечность заметно опухает [6, с. 67]. При лечении применяют спиртовые повязки. При необходимости специалисты прибегают к аспирации экссудата. В полость бурсы вводится 5\% спиртовой раствор йода. Лечение гнойный формы заболевания заключается в удалении омертвевших тканей. Ветеринарный врач проводит вскрытие бурсы. Следующим этапом является выскабливание слизистой оболочки. После этого в пораженный сустав вводят раствор Фурацилина или Сульфацила. Полость заполняется марлевыми тампонами, пропитанными прижигающими растворами. Чтобы снять боль используется раствор Новокаина. Остановить воспалительный процесс можно за счёт применения препаратов Пенициллина или Стрептомицина. Провоцирующими факторами являются травмы от ударов или ушибов, инфекционные заболевания, а также ограниченное пространство, в котором животные могут травмировать друг друга. 


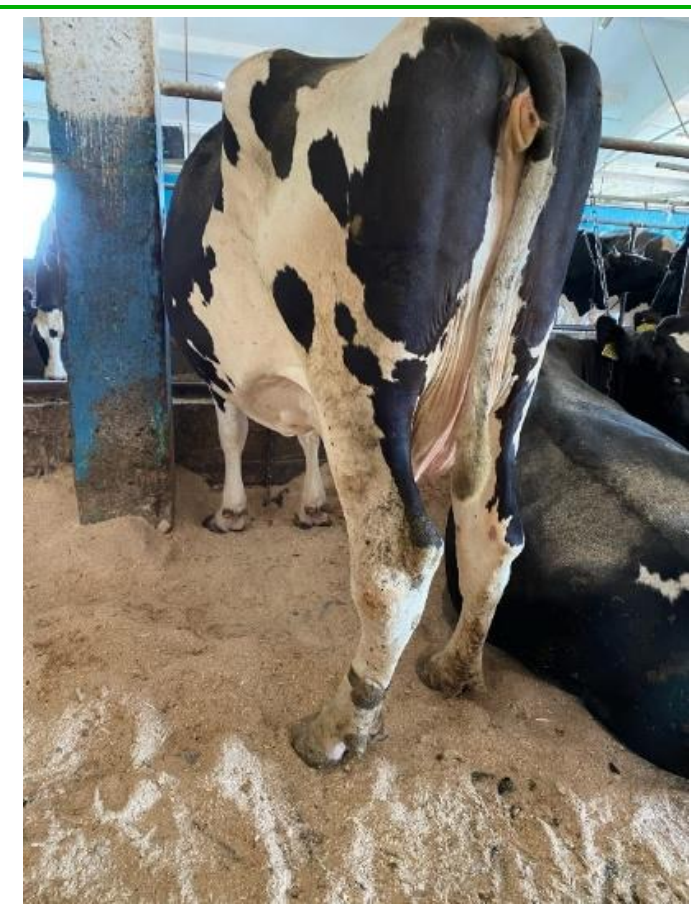

\section{Рис. 9. Бурсит тарсального сустава у коровы}

Основными мерами профилактики инфекционных и неинфекционных заболеваний на территории двух хозяйств являются: соблюдение ветеринарносанитарных норм, правил асептики и антисептики, регулярное проведение уборок в помещении, а также вакцинация. Основные применяемые вакцины: вакцина ОКЗ (ассоциированная инактивированная против колибактериоза, сальмонеллеза, клебсиеллеза и протейной инфекции молодняка сельскохозяйственных животных и пушных зверей), Инфорс 3 (предназначена для профилактики ринотрахеита, парагриппа-3 и респираторносинцитиальный инфекций крупного рогатого скота.), Ротавекс Корона (против ротавирусной, коронавирусной инфекций и эшерихиоза молодняка крупного рогатого скота инактивированная эмульгированная) и другие.

Таким образом, в ходе работы были выявлены и охарактеризованы особенности беспривязного и комбинированного содержания крупного рогатого скота, кормления, вакцинирования, содержания телят. Определено, что для 1-ого хозяйства с беспривязным содержанием было характерно левостороннее смещение сычуга у коров после отела, а для 2-ого хозяйства при комбинированном содержании животных - бурсит тарсального сустава и переостит. 


\section{Список литературы}

1. Веремей, Э.И. Влияние экзогенных факторов на состояние здоровья и продуктивность коров молочных комплексов / Э.И. Веремей, В.М. Руколь, А.П. Волков, А.А. Стекольников, Б.С. Семенов // Актуальные проблемы ветеринарной хирургии: материалы Международной научной конференции 67 октября 2011 г.- Ульяновск, 2011. - C.20-30.

2. Shewbridge Carter L., Rutter S. M., Ball D., Gibbons J., Haskell M. J. Dairy cow trade-off preference for 2 different lying qualities: Lying surface and lying space // J Dairy Sci / 2021 Jan;104(1):862-873. doi: 10.3168/jds.2020-18781. Epub 2020 Oct 31.

3. McPherson S.E., Vasseur E. Graduate Student Literature Review: The effects of bedding, stall length, and manger wall height on common outcome measures of dairy cow welfare in stall-based housing systems // J Dairy Sci /2020 Nov;103(11):10940-10950. doi: 10.3168/jds.2020-18332. Epub 2020 Sep 18.

4. Семенов, Б.С. Оперативная хирургия у животных: учебное пособие / Б.С. Семенов, В.Н. Виденин, А.Т. Вощевоз, Т.Ш. Кузнецова, Е.В. Рыбин, К.В. Титов. - М.: КолосС, 2012. - 423 с.

5. Стекольников А.А., Семенов Б.С., Букаи М., Виденин В.Н., Кузнецова Т.Ш., Грибова М.А. Клинические результаты оперативного лечения коров при смещении сычуга / Сборник научных трудов девятой межвузовской конференции по клинической ветеринарии в формате Purina partners, посвященной 100-летию московской ветеринарной академии. - 2019. c. $65-67$

6. Марьин, Е.М. Характеристика ортопедических патологий у крупного рогатого скота / Е.М. Марьин, В.А. Ермолаев, О.Н. Марьина, И.С. Раксина // Вестник Ульяновской государственной сельскохозяйственной академии. 2012. - No 4. - C. 66-69.

(C) Губернаторова B.A.,2021 